uptake of speech therapy throughout Britain suggests that families of lower social class are making worse use of the speech therapy provisions available in their vicinity.

Detailed analysis was made of a high-risk group of children, comprising $1.6 \%$ of all the 7-year-olds, who were considered to have a marked speech defect in the absence of any auditory difficulty after evaluation of a large amount of data available on speech and hearing from doctor, teacher, and health visitor and assessment of test results. Even though this was clearly a very handicapped group not more than a third were reported as having been referred by 7 years for speech therapy. It would have been interesting to have considered these children under aetiological headings, but the absence of specialized tests to assist differential diagnosis inevitably led to the bracketing of many different conditions under the heading of marked speech defect. These included true language disorders and dysarthrias of every type, as well as late-resolving developmental phonetic substitutions which would normally have disappeared spontaneously by the age of 7 years. Nevertheless, when considered as a group these children did manifest a number of important sociobiological characteristics. These children, more often males, came from a poorer social background and were of later birth order than controls. Apart from aetiological considerations such findings help to define the type of child worthy of further investigations of their speech problems. The children more often showed other disabilities, such as visual defect or squint, emphasizing the need for searching for other handicaps. They were more often rated as being clumsy by their teachers, perhaps indicating that a proportion might be associated with neurodevelopmental dysfunction. Perinatal factors were sought, but apart from the tendency for these children to be born before term abnormalities of pregnancy or labour were not found to be significantly more common than in controls.

Over a third of the children with marked speech defect were recognized by 7 years of age to have educational difficulties. It was not unexpected, therefore, that the whole group showed a poorer performance on teachers' ratings as well as on tests of visuomotor ability and social adjustment. When the 82 children with recognized educational difficulties were excluded, on the grounds that educationally backward children often have poorly developed speech, the remaining $60 \%$ of children with marked speech defect still performed unsatisfactorily in the majority of the tests compared with controls. Clearly many children in normal schools with speech defects have an educational problem at 7 years which requires special consideration. The educational complications and possible lines of therapy should always initially be discussed with the child's teacher.

On the evidence available from these results there can be no question that children with speech defects at 7 years need and should be urgently provided with expert treatment and followup by speech therapists, not working in isolation but in conjunction with paediatricians, psychologists, psychiatrists, teachers, and parents.

We should like to thank the local authority medical officers and teachers without whose help this investigation would not have been possible. We should also like to thank the National Children's Bureau, who mounted the National Child Development Study, and also $\mathrm{Mr}$. A. P. Round for statistical help. This work was supported by a grant from the National Fund for Research into Crippling Diseases.

\section{References}

Alberman, E. D., Butler, N. R., and Sheridan, M. D. (1971). Developmental mental Medicine and Child Neurology, 13,9.

Butler, N. R., and Alberman, E. D. (1969). In Perinatal Problems. Edinburgh, Livingstone.

Butler, N. R., and Bonham, D. G. (1963). In Perinatal Mortality. Edinburgh, Livingstone.

Davie, R., Butler, N. R., and Goldstein, H. (1972). From Birth to Seven. London, Longman, in association with the National Children's Bureau. Fiedler, Miriam F., Lennenberg, Eric M., Rolfe, Ursula, and Drorbaugh, James E. (1971). Pediatrics, 48, 2.

Harris, D. B. (1963). Children's Drawings as Measures of Intellectual Maturity; a Revision and Extension of the Goodenough Draw-a-man. Test. London, Harrap.

Ingram, T. T. S. (1972). Proceedings of the Royal Society of Medicine, 65, 404. Morley, M. E. (1965). The Development of Disorders of Speech in Childhood. London, Livingstone.

Pringle, M. L. K., Butler, N. R., and Davie, R. (1966). 11,000 Seven-year Olds. London, Longman.

Sheridan, Mary D. (1948). The Child's Hearing for Speech. London, Methuen

Stott, D. H. (1958). The Social Adjustment of Children (Manual to the Bristol Social Adjustment Guides). London, University of London Press.

\title{
Early Mobilization after Myocardial Infarction: a Controlled Study
}

\author{
H. J. LAMERS, W. S. J. DROST, \\ W. H. BIRKENHÄGER \\ B. J. M. KROON, \\ L. A. vaN ES, \\ L. J. MEILINK-HOEDEMAKER,
}

British Medical fournal, 1973, 1, 257-259

course and laboratory data. In neither group was there a fatal complication and the differences in clinical outcome or laboratory data were statistically not significant. Half of the patients from each group were re-examined after an average of one-and-a-half years, and again no differences were observed. It is concluded that patients with an uncomplicated myocardial infarction may safely be mobilized after 9 days and discharged after three weeks.

Department of Internal Medicine, Zuiderziekenhuis, Rotterdam, Netherlands

H. J. LAMERS, Senior Registrar

W. S. J. DROST, Resident

B. J. M. KROON, Resident

L. A. VAN ES, M.D., Resident

L. J. MEILINK-HOEDEMAKER, Resident

W. H. BIRKENHÄGER, M.D., Head of Department

\section{Introduction}

Patients who sustain a myocardial infarction traditionally face a fixed period of bed rest, usually amounting to six weeks, irrespective of the severity of their condition. In recent years, however, a small degree of mobilization has been advocated as 
soon as the acute symptoms have subsided. It is argued that thromboembolic complications and other sequelae of immobility might thus be averted. Objections are that early mobilization might disturb the consolidation of the infarcted area, thus giving rise to aneurysm formation and other hazards. Controlled studies on this vital issue are remarkably scarce (see Discussion).

In 1967 we started a pilot study. The preliminary results in 144 patients were encouraging enough for us to carry out a more extensive investigation, and this ran from March 1968 to August 1971 and included 203 patients.

\section{Subjects and Method}

From March 1968 to August 1971844 patients with possible myocardial infarction were admitted to hospital. Of these, 555 satisfied at least two of the following criteria: (1) characteristic clinical presentation, (2) presence of $Q$ waves, $S-T$ elevation, or $T$-wave inversion with evolutionary changes, and (3) a rise in either serum aspartate aminotransferase or lactic dehydrogenase or both. Additional criteria were fever, leucocytosis, and a rising E.S.R. From November 1968 they were monitored at the coronary care unit. Up to the 10 th day all patients received identical basic treatment-namely, bed rest, anticoagulants, and low-salt diet. The clinical condition and the laboratory data were reviewed on day 9 by a special team. By delaying the allocation to the latest possible moment we hoped to minimize secondary drop-out problems.

The following criteria were used for admission to the study: absence of chest pain from day 5, stabilization of the infarcted area according to the electrocardiograms, no serious rhythm or conduction disturbances after the third day, no fever, no gross rise in either serum lactic dehydrogenase or aspartate aminotransferase, systolic blood pressure $90 \mathrm{~mm} \mathrm{Hg}$ or more, pulse pressure $25 \mathrm{~mm} \mathrm{Hg}$, central venous pressure (Lewis-Borst) not more than $\mathrm{R}-3 \mathrm{~cm}$, and the absence clinically of pulmonary congestion. Patients finally admitted to the trial were allocated to two groups. Those in group 1 were mobilized on day 10 and those in group 2 on day 20. The procedure of mobilization for group 1 was as follows: day 10, dangling the legs for 15 minutes; day 11 , sitting in a chair for 15 minutes; day 12, sitting for 30 minutes; day 13, sitting for one hour; day 14, two one-hour periods of ambulancy; day 15, two one-and-a-half hour periods of ambulancy in the ward; day 16, two two-hour periods of ambulancy; and from day 17 onwards, free walks through the corridors and halls. The schedule for group 2 was identical, starting on day 20 . Smoking and watching football on television were prohibited during the entire observation period.

\section{Results}

Altogether 352 of the 555 patients did not enter the study119 died in the run-in period and 147 were thought unsuitable because of clinical hazards and 86 because of statistical problems. Of the 203 patients who were admitted to the trial 103 were allocated to group 1 and 100 to group 2 . In group 1 one patient had to be dropped at the last moment because of reinfarction one hour before she was due to be mobilized.

Group 1 thus comprised 102 patients ( 72 men and 30 women) and group 2100 patients ( 74 men and 26 women). The age and sex distribution was nearly identical, though in the highest decade women predominated in group 1 and men in group 2 (table I). The differences in clinica! outcome during the hospital stay of 30 days were not statistically significant (table II). We gained the impression that patients in group 1 fared psychologically better than those in group 2 . A profile of relevant laboratory data in both groups is shown in the chart. A number of patients in group 1 exhibited a slight increase in serum lactic dehydrogenase and creatinine values at the end of the first mobilization period (compared with patients in group 2, who were still recumbent), possibly due to a decreased hepatic and
TABLE I-Age and Sex Distribution

\begin{tabular}{|c|c|c|c|c|}
\hline \multirow{2}{*}{ Age (Years) } & \multicolumn{2}{|c|}{ Group 1 (102 Patients) } & \multicolumn{2}{|c|}{ Group 2 (100 Patients) } \\
\hline & Men & Women & Men & Women \\
\hline $\begin{array}{l}30-39 \\
40-49 \\
50-59 \\
60-69 \\
70-79 \\
80-89\end{array}$ & $\begin{array}{r}2 \\
8 \\
19 \\
24 \\
18 \\
1\end{array}$ & $\begin{array}{l}1 \\
1 \\
8 \\
7 \\
6 \\
7\end{array}$ & $\begin{array}{r}4 \\
10 \\
18 \\
24 \\
12 \\
6\end{array}$ & $\begin{array}{r}0 \\
1 \\
5 \\
10 \\
9 \\
1\end{array}$ \\
\hline Total & 72 & 30 & 74 & 26 \\
\hline
\end{tabular}

TABLE II-Complications occurring from Day 10 onward

\begin{tabular}{|c|c|c|c|c|c|c|}
\hline & & & & & Group 1 & Group 2 \\
\hline $\begin{array}{l}\text { Further infarction } \\
\text { Pulmonary embolism } \\
\text { Abnormal cardiac rhythm } \\
\text { Period(s) of angina } \quad \text {.. }\end{array}$ & $\begin{array}{l}\cdots \\
\ddot{*}\end{array}$ & $\begin{array}{l}. \\
\because \\
\cdots\end{array}$ & $\begin{array}{l}\because \\
\because \\
\cdots\end{array}$ & $\begin{array}{l}\because \\
\because \\
.\end{array}$ & $\begin{array}{l}1 \\
1 \\
2 \\
6\end{array}$ & $\begin{array}{l}0 \\
1 \\
1 \\
3\end{array}$ \\
\hline
\end{tabular}
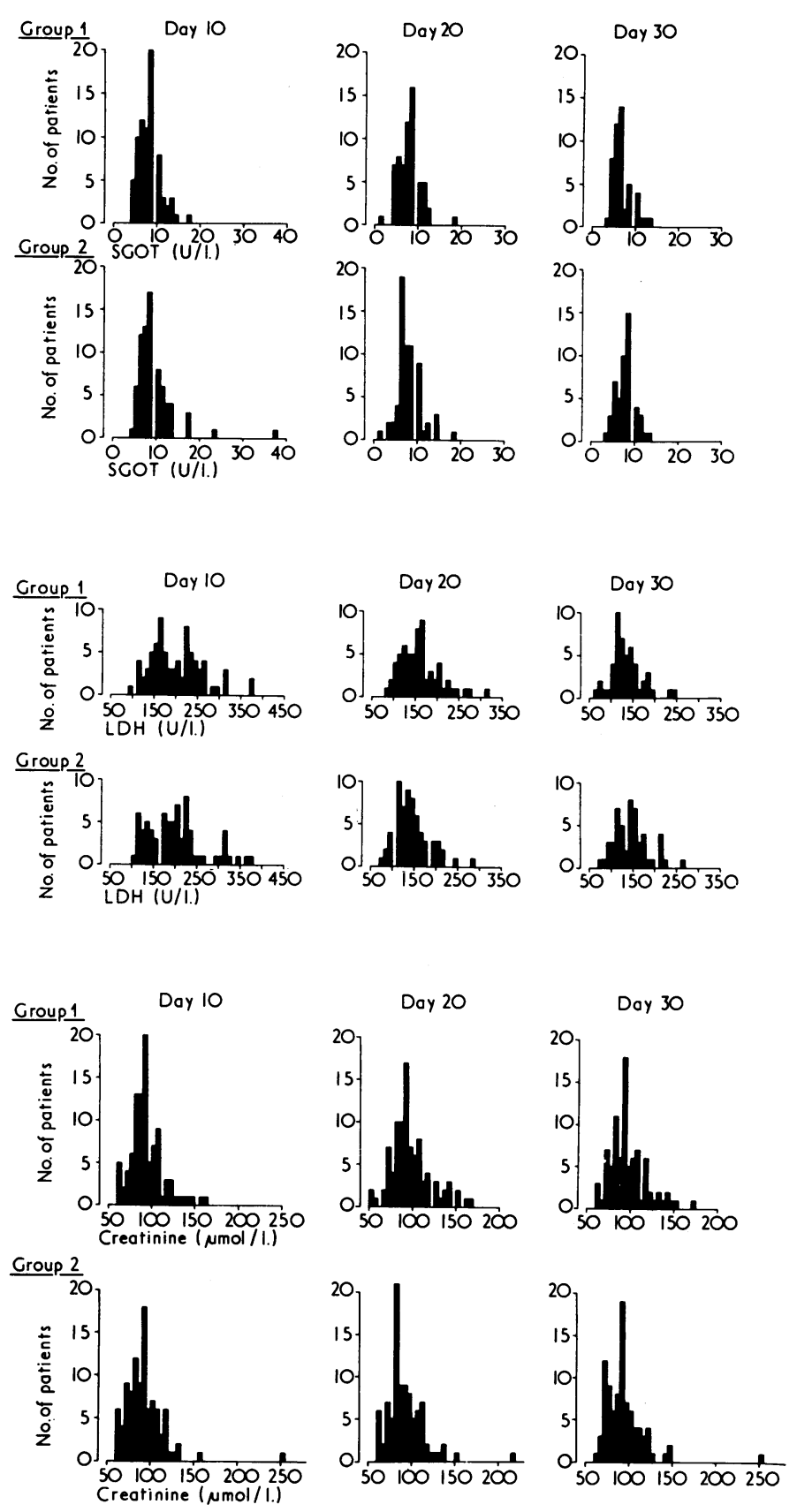

Distribution curves of serum levels of aspartate aminotransferase (SGOT), lactic dehydrogenase (LDH), and creatinine in the two groups of patients.
Profiles were similar in both groups on days 10 and 30 . 
renal perfusion rate as a consequence of orthostatic circulatory insufficiency. These shifts, however, were statistically not significant, and on day 30 the profiles were identical in both groups.

The late sequelae of early mobilization were evaluated by follow-up of half of the patients in each group. After an average of one-and-a-half years no significant differences were found (table III). Seventeen patients in group 1 had died after an average of 11 months and 15 in group 2 after they had survived for an average of 13 months.

TABLE III-Follow-up Data

\begin{tabular}{l|c|c|c|c|c|c}
\hline & $\begin{array}{c}\text { No. } \\
\text { of } \\
\text { Patients }\end{array}$ & $\begin{array}{c}\text { Average } \\
\text { Interval } \\
\text { (Months) }\end{array}$ & $\begin{array}{c}\text { Cardiac } \\
\text { Aneurysm }\end{array}$ & $\begin{array}{c}\text { Congest- } \\
\text { ive } \\
\text { Heart } \\
\text { Failure }\end{array}$ & $\begin{array}{c}\text { Severe } \\
\text { Angina }\end{array}$ & Dead \\
\hline Group 1 & 50 & 19 & - & 6 & 9 & 8 \\
Group 2 & 48 & 18 & 2 & 5 & 6 & 9 \\
\hline
\end{tabular}

\section{Discussion}

To our knowledge only two other controlled studies of this kind have been carried out. Groden et al. (1967) compared the clinical course after 15 and 25 days of bed rest. They allocated patients at an early stage. A number of patients could not be mobilized according to schedule because of complicating events. Thus the two groups became unequal in size and a statistical bias was introduced. The rate of complication did not differ between the two groups. Harpur et al. (1971) ran a trial on patients who were mobilized on the 8th and 21st days and found no differences in clinical course. A complete clinical comparison was not possible because patients in the first group were discharged on the 15th day. At follow-up after eight months, however, patients from the former group appeared to have fared no worse than those from the latter group.

The results of these studies and the present one indicate that patients with an uncomplicated myocardial infarction may safely be mobilized after one to two weeks and discharged after about three weeks.

We are indebted to Sister A. J. Alblas-Goedegebuure, Sister J. A. v.d. Krans, Miss B. L. Spildooren, Miss A. H. v.d. Hoest, Miss J. A. Spijkman, Miss J. W. Schouls, Miss M. A. Poesse, Miss J. E. Schot, and Mr. R. O. Hatt for invaluable help.

Requests for reprints should be addressed to Dr. W. H. Birkenhäger, Department of Internal Medicine, Zuiderziekenhuis, Groeneveld 15, Rotterdam, Netherlands.

\section{References}

Groden, B. M., Allison, A., and Shaw, G. B. (1967). Scottish Medical fournal, $12,435$.

Harpur, J., et al. (1971). Lancet, 2, 1331.

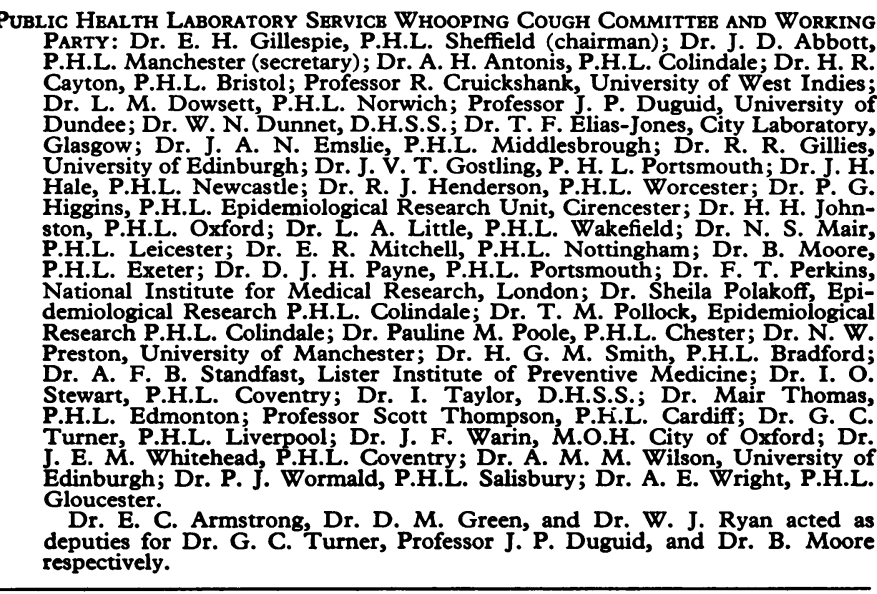

unvaccinated contacts was $69 \%$. These findings suggest that much of the pertussis vaccine in use for five or six years before 1968 was not very effective. However, vaccine from one producer was more effective than vaccine from another. Of the cultures of $B$. pertussis identified $89 \%$ were serotype 1,3 and only about $9 \%$ were serotype $1,2,3$. Serotype 1, 2, 3 was isolated much more frequently from unvaccinated than from vaccinated children, but some cultures identified as type $1,2,3$ were found on re-examination to contain colonies of type 1,3 . Virological investigations were made in some areas during the first year of the study. Of the wide variety of viruses identified adenovirus and parainfluenza virus were the most common groups. Virus isolation rates were similar in patients and symptomless contacts, but $B$. pertussis was isolated far more often from patients than from symptomless contacts. The evidence suggests that $B$. pertussis remained the major cause of whooping cough in the U.K.

\section{Introduction}

In November 1966 a Public Health Laboratory Service working party began an investigation to identify the serotypes of Bordetella pertussis currently responsible for whooping cough and to assess the efficacy of the pertussis vaccines in use before and during the period of the study. In some areas an attempt was made to isolate viruses from the patients. A preliminary report (P.H.L.S., 1969) of the first year's results suggested that much of the pertussis vaccine in general use for some years before 1968 was not very effective. 